\title{
Immunoglobulin Response and Prognostic Factors in Repeated SARS-CoV-2 Positive Patients: A Systematic Review and Meta-Analysis
}

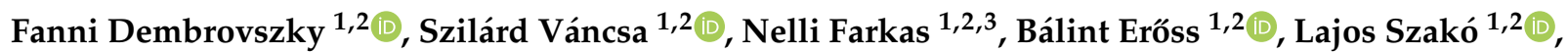

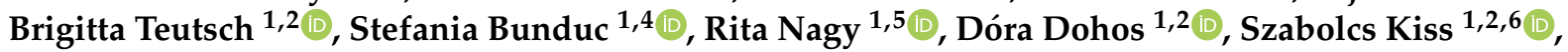 \\ Andrea Párniczky ${ }^{1,5}$, Zsófia Vinkó $^{1}$, Zoltán Péterfi ${ }^{7, *}$ and Péter Hegyi ${ }^{1,2, *}$
}

Citation: Dembrovszky, F.; Váncsa S.; Farkas, N.; Erőss, B.; Szakó, L.; Teutsch, B.; Bunduc, S.; Nagy, R.; Dohos, D.; Kiss, S.; et al. Immunoglobulin Response and Prognostic Factors in Repeated SARS-CoV-2 Positive Patients: A Systematic Review and Meta-Analysis. Viruses 2021, 13, 809. https://doi.org/10.3390/v13050809

Academic Editor:

Luis Martinez-Sobrido

Received: 16 March 2021

Accepted: 27 April 2021

Published: 30 April 2021

Publisher's Note: MDPI stays neutral with regard to jurisdictional claims in published maps and institutional affiliations.

Copyright: (c) 2021 by the authors. Licensee MDPI, Basel, Switzerland. This article is an open access article distributed under the terms and conditions of the Creative Commons Attribution (CC BY) license (https:// creativecommons.org/licenses/by/ $4.0 /$ )
1 Institute for Translational Medicine, Medical School, University of Pécs, 7624 Pécs, Hungary; dembrovszky.f@gmail.com (F.D.); vancsaszilard@gmail.com (S.V.); farkas.nelli@gmail.com (N.F.); dr.eross.balint@gmail.com (B.E.); szaklaj@gmail.com (L.S.); teutschbrigitta@gmail.com (B.T.); stfnbndc@gmail.com (S.B.); nagyrita003@gmail.com (R.N.); dohos.dora@gmail.com (D.D.); kissszabolcs1995@gmail.com (S.K.); andrea.parniczky@gmail.com (A.P.); vinkozsofi@gmail.com (Z.V.)

2 János Szentágothai Research Center, University of Pécs, 7624 Pécs, Hungary

Institute of Bioanalysis, Medical School, University of Pécs, 7624 Pécs, Hungary

4 Gastroenterology, Hepatology and Liver Transplant Department, Fundeni Clinical Institute, Bucharest 022328, Romania

5 Heim Pál Children's Hospital, 1089 Budapest, Hungary

6 Doctoral School of Clinical Medicine, University of Szeged, 6720 Szeged, Hungary

7 Division of Infectious Diseases, First Department of Medicine, Medical School, University of Pécs, 7623 Pécs, Hungary

* Correspondence: peterfi.zoltan@pte.hu (Z.P.); hegyi2009@gmail.com (P.H.)

\begin{abstract}
With repeated positivity being an undiscovered and major concern, we aimed to evaluate which prognostic factors may impact repeated SARS-CoV-2 positivity (RSP) and their association with immunoglobulin detectability among recovered patients. A systematic literature search was performed on 5 April 2021. Cohort studies with risk factors for repeated RSP or information about the immunoglobulin response (immunoglobulin $\mathrm{M}(\mathrm{IgM})$ and/or immunoglobulin $\mathrm{G}(\mathrm{IgG})$ ) were included in this analysis. The main examined risk factors were severity of the initial infection, body mass index (BMI), length of hospitalization ( $\mathrm{LOH})$, age, and gender, for which we pooled mean differences and odds ratios (ORs). Thirty-four cohort studies $(N=9269)$ were included in our analysis. We found that increased RSP rate might be associated with IgG positivity; IgG presence was higher in RSP patients (OR: 1.72, CI: 0.87-3.41, $p=0.117$ ). Among the examined risk factors, only mild initial disease course showed a significant association with RSP (OR: 0.3, CI: 0.14-0.67, $p=0.003$ ). Age, male gender, BMI, LOH, and severity of the first episode do not seem to be linked with repeated positivity. However, further prospective follow-up studies focusing on this topic are required.
\end{abstract}

Keywords: COVID-19; meta-analysis; prognosis; repositivity; SARS-CoV-2

\section{Introduction}

More than one year after the outbreak of the severe acute respiratory syndrome coronavirus 2 (SARS-CoV-2) pandemic, the number of confirmed infections exceeds 100 million and it has caused over 2 million deaths [1,2]. Some viral infections can lead to life-long immunity, such as morbilli, mumps and rubella, with low antigenic variability [3]. However, a single first episode of coronavirus disease 2019 (COVID-19) might not prevent a recurrence, and previous reports and a meta-analysis stipulated the possibility of reinfection [4-7].

A study found that recurring SARS-CoV-2 polymerase chain reaction (PCR) positivity might occur in $2.4 \%$ to $69.2 \%$ of the patients [2]. However, reinfection is not defined by an international consensus. Repeated PCR positivity might result from relapse of the 
disease, false positivity, or reinfection. Positivity may also be caused by the remaining viral fragments in the case of a PCR with a high cycle threshold [8].

The literature is contradictory, considering both the potential existence of reinfection and patients' infectivity with repeated PCR positivity. A narrative review and a Korean study suggest that repeated positivity might not be associated with infectious state [2]. Furthermore, a study found that reinfection cannot occur in Rhesus macaques [9]. The meta-analysis of Arafkas et al. concluded that the persistence of test positivity is caused by a prolonged disease course rather than reinfection [10]. On the other hand, among the several case reports on patients with possible reinfection, very few differentiated between the strains of SARS-CoV-2.

Considering reinfection, one of the main questions is whether specific antibodies provide immunity against a second episode. Anti-SARS-COV-2 Immunoglobulin G (IgG) positivity was found in more than $95 \%$ of the patients after the recovery from the infection [11] Despite this, there is still no consensus whether they are protective for the second episode of disease and serology data for the repositive cases are lacking. Based on the literature RSP, an earlier confirmed COVID-19 patient produces a repeatedly positive RS-PCR test after two consecutive negative results (with at least a $24 \mathrm{~h}$ sampling interval) of the nucleic acid tests of respiratory pathogens during the follow-up period [12]. Lumley et al. investigated the relationship between antibody positivity and the risk of SARS-CoV-2 reinfection in a prospective cohort study and showed that the presence of IgG antibodies reduces the risk of further infection [13].

While clear definitions are missing considering the meaning of a PCR positivity after a negative test, a recurring disease's clinical importance should be highlighted. The probability of disease recurrence in COVID-19 patients is a significant concern, and the relevance of PCR repositivity needs to be better understood in terms of causes and predisposing factors. A Danish population-level observational study examined the factors that protect against reinfection and found that $80 \%$ of younger people ( $<65$ years) are protected compared to $47 \%$ of older people ( $>65$ years) [14]. However, we are not yet aware of prognostic factors potentially influencing the recurrence of positive results of PCR.

In this meta-analysis of cohort studies, we aimed to assess the prognostic factors for repeated SARS-CoV-2 positive episodes (RSPs) and the prognostic value of immunoglobulin positivity (seroconversion).

\section{Materials and Methods}

The study protocol of the systematic review and meta-analysis was registered to the International Prospective Register of Systematic Reviews (PROSPERO) with the registration number CRD42021233618 (see https: / / www.crd.york.ac.uk/ prospero, accessed on 29 March 2021). It was performed adhering to the guidelines established by Preferred Reporting Items for Systematic Reviews and Meta-Analyses (PRISMA) [15]. Protocol deviation did not occur.

\subsection{Search}

A systematic literature search was conducted in Cochrane Central Register of Controlled Trials (CENTRAL), Embase and MEDLINE (via PubMed) for studies published from inception to 5 April 2021. The following search key was applied: (("covid 19") OR ("coronavirus") OR ("2019 nCoV") OR ("SARS-cov-2")) AND ((reinfection) OR ("second episode") OR ("second infection") OR (reactivation) OR (recurrence) or (relapse) OR (repositive) OR (re-detectable) OR (retest-positive) OR (repeated infection)). No language or other restrictions were imposed.

\subsection{Selection and Eligibility}

Duplicate removal of yielded articles was performed by a reference management program (EndNote X9, Clarivate Analytics, Philadelphia, PA, USA). Two independent researchers (BT, SB) followed the Cochrane Handbook's recommendation [16] and simul- 
taneously screened the titles, abstracts, and full texts of the included studies based on predetermined criteria. Cohort studies were eligible for our meta-analysis where authors reported data of patients characterized with any of the terms included in our search key, referring to an RSP. We included only those cohort studies in which any of the characteristics (age, gender, the severity of the initial infection, body mass index, length of hospital stay, antibody presence) of RSP versus non-RSP patients were compared. In case of any disagreement, a consensus was reached after discussion with a third author.

\subsection{Data Collection}

Two review authors extracted the data independently (BT, SB) into a pre-defined Excel datasheet (Office 365, Microsoft, Redmond, WA, USA). An independent third party (FD) settled any discrepancies. The following data were collected from each study: first author, digital object identifier (DOI), study site (country), study design, study period, patient follow-up period, definitions regarding examined patients and events, hospital discharge criteria, demographic data of the whole study population and the repeatedly positive and control groups, days between first and second SARS-CoV-2 positive tests. Data regarding age and sex of the patients, the severity of COVID-19, body mass index (BMI), length of hospitalization (LOH), IgM, and IgG positivity were extracted for both RSP and non-RSP groups.

\subsection{Risk of Bias and Quality Assessment}

Based on the recommendation of the Cochrane Prognosis Methods Group [17], the Quality in Prognostic Studies (QUIPS) tool [18] was applied separately by two authors (RN, DD) to assess the methodological quality of the included studies. Any disagreement was resolved by arbitration by a third investigator.

\subsection{Statistical Analysis}

All meta-analytical calculations were performed by Stata v15.1 software (Stata Corp LLC, College Station, TX, USA). In the case of dichotomous outcomes, odds ratios (ORs) with their 95\% confidence intervals (CIs) and weighted mean differences (WMDs) with 95\% CIs were calculated for continuous outcomes. Pooled estimates were calculated with the randomeffects model using the DerSimonian-Laird estimator [19]. A p-value of less than 0.05 was considered a statistically significant result.

Statistical heterogeneity was analyzed using the $\mathrm{I}^{2}$ and $\chi^{2}$ tests. $\mathrm{I}^{2}$ values, representing the magnitude of heterogeneity, were interpreted as moderate (30-60\%), substantial $(50-90 \%)$, or considerable (75-100\%). The $p$-value of less than 0.10 was defined as indicating significant heterogeneity [20]. Publication bias was assessed by Egger's test and by visual inspection of funnel plot asymmetry (alpha $=0.1)$ when at least ten studies were available.

\section{Results}

\subsection{Search and Selection}

Our search strategy yielded 4627 studies from the three databases. After duplicate removal, we screened 3249 articles by title, abstract and full text, out of which 34 [12,21-54] were eligible for meta-analysis. No additional reports were identified in the primary eligible studies' reference lists. The search and selection process are presented in Figure 1. 

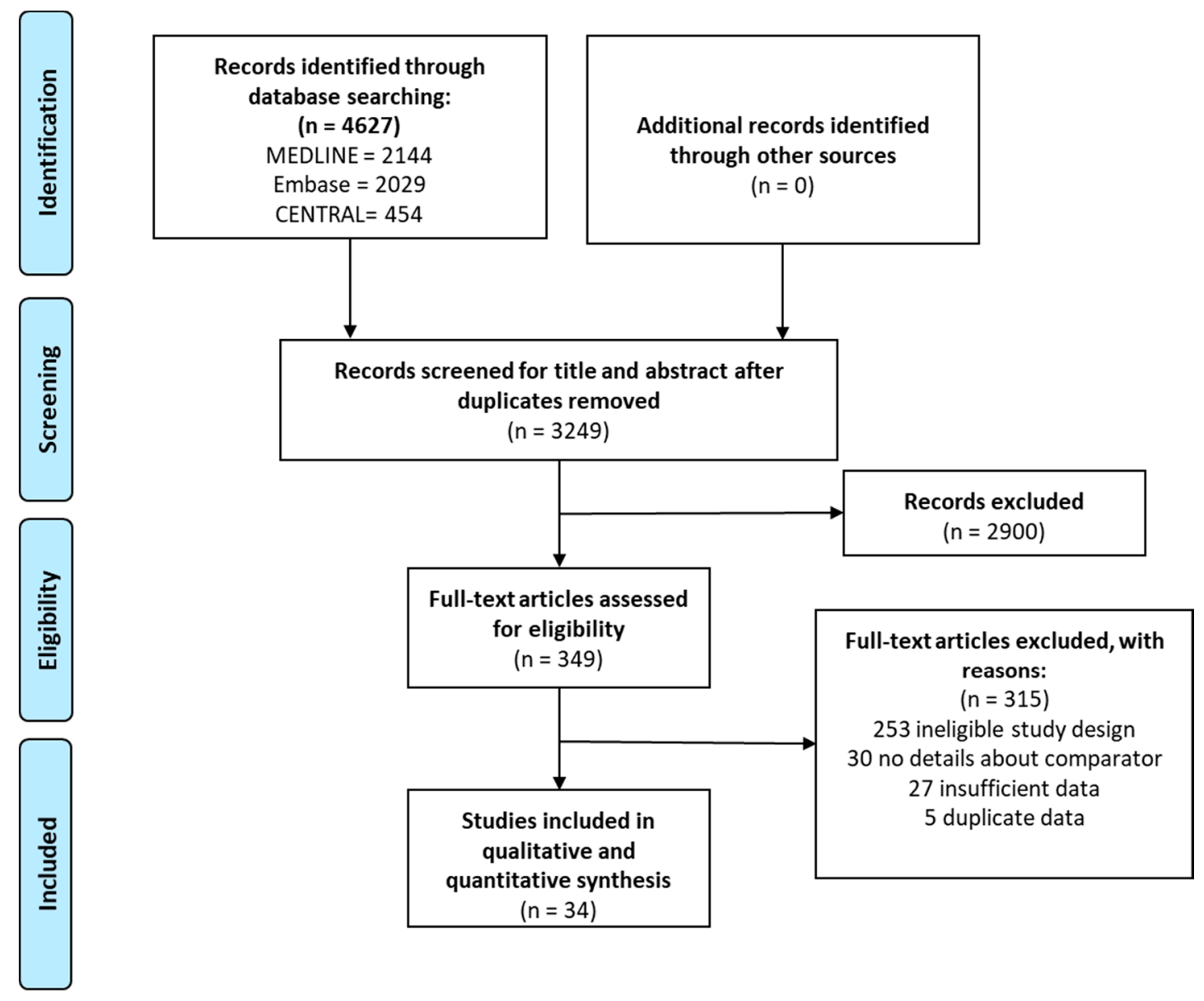

Figure 1. PRISMA flowchart showing the process of systematic search and article selection.

\subsection{Characteristics of the Studies Included}

The basic characteristics of the included articles are summarized in Table 1. Out of the 34 included articles, 33 were from China [12,21-29,31-55] and 1 from Italy [30]. All of the included studies were conducted during the first wave of the COVID-19 pandemic. Three of them were prospective cohort studies; the rest were retrospective analyses. The proportion of patients with RSP ranged from $2.38 \%$ to $58.63 \%$. The follow-up period of patients ranged from 14 to 58 days in the included studies. Data about the PCR and antigen detection techniques are in the Supplementary Material (Tables S1 and S2).

\subsection{Quantitative Synthesis}

Our meta-analysis included 34 studies with 9269 patients reporting on 1490 repeatedly positive SARS-CoV-2 patients; the mean rate of the repositive cases was $16.08 \%$.

\subsubsection{Immunoglobulins}

Based on five articles, IgM positivity did not differ between the RSP positive and RSP negative groups (Figure 2) (OR: 0.92, CI: 0.55, 1.53, $p=0.737$ ), IgM levels were positive in $125 / 292$ RSP patients $(42.81 \%)$ and $401 / 913$ non-RSP patients $(43.92 \%)$. Heterogeneity for IgM was substantial $\left(\mathrm{I}^{2}: 60.5, p=0.019\right)$ (Figure 2$)$. 
Table 1. Basic characteristics of the included studies.

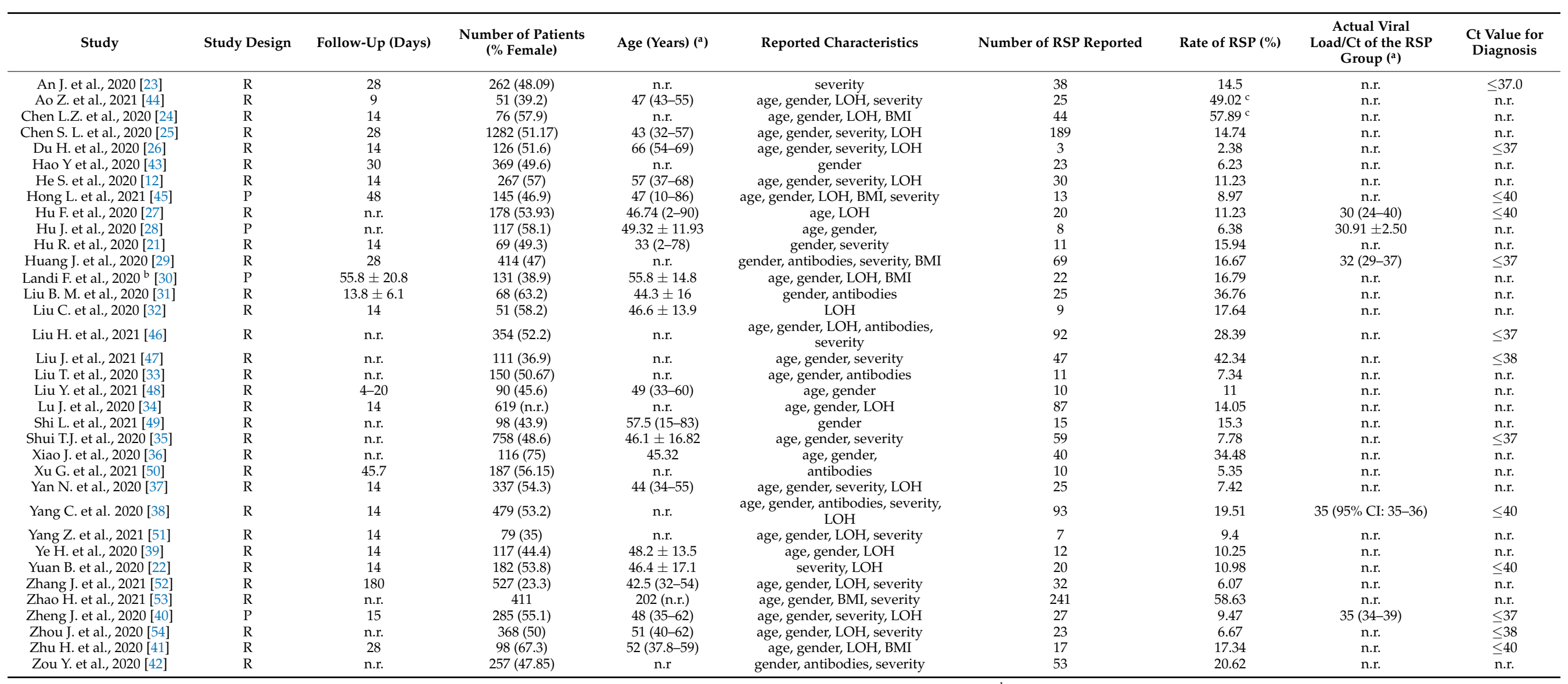

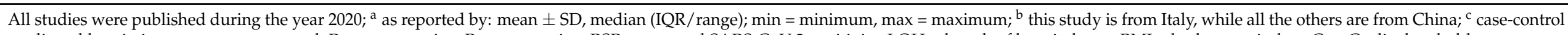
studies, abbreviations: $n . r .=$ not reported, $\mathrm{R}=$ retrospective; $\mathrm{P}=$ prospective; $\mathrm{RSP}=$ repeated SARS-CoV-2 positivity, $\mathrm{LOH}=$ length of hospital stay; $\mathrm{BMI}=$ body mass index.; $\mathrm{Ct}=\mathrm{Cyclic}$ threshold. 


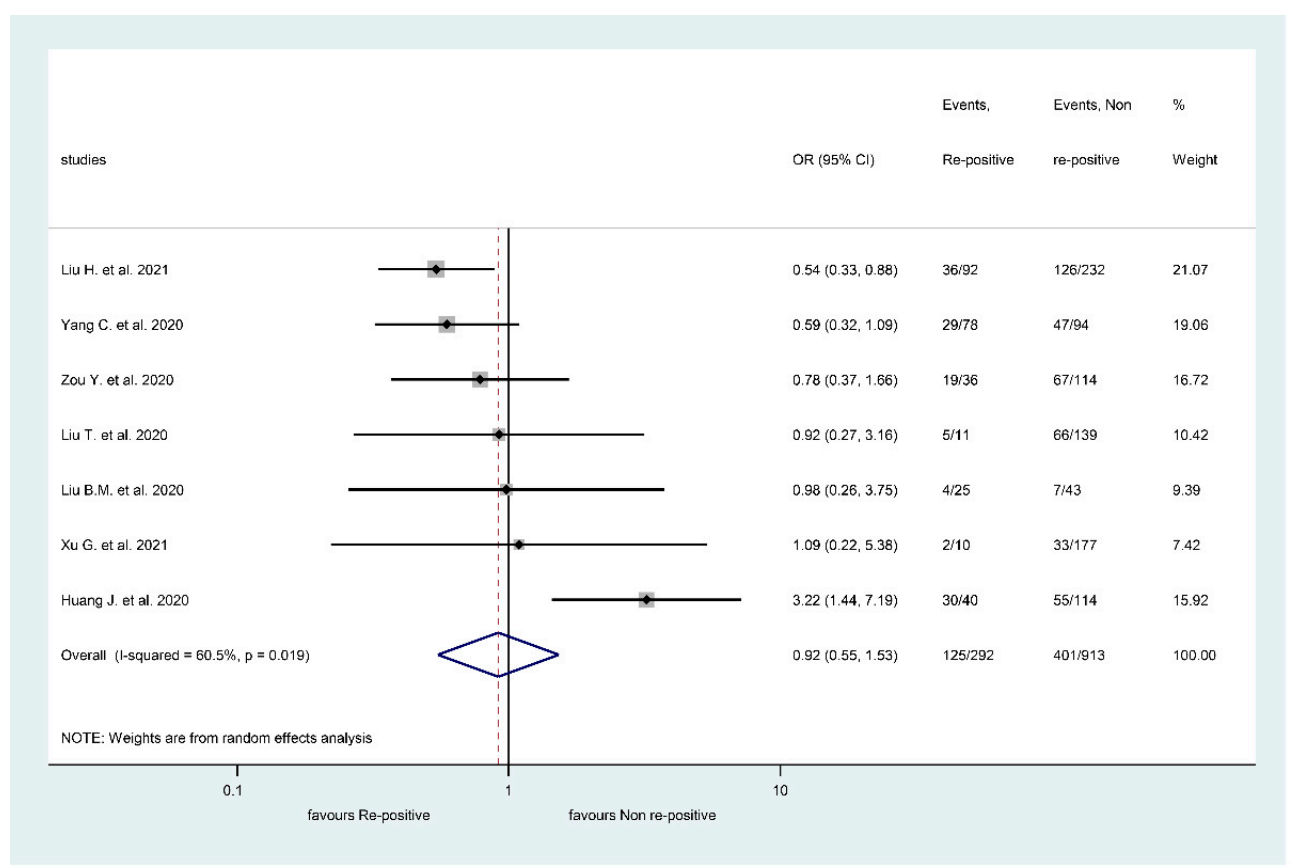

Figure 2. Forest plot representing that repeatedly SARS-CoV-2 positive episode does not significantly impact Immunoglobulin M's presence.

However, IgG positivity was associated with a higher RSP rate, but the difference was not statistically significant (Figure 3) (OR: 1.72, CI: 0.87, 3.41, $p=0.117$ ). IgG levels were positive in $277 / 289$ RSP patients $(95.85 \%$ ) and $828 / 913$ non-RSP patients $(90.69 \%)$. Heterogeneity was not present in the case of $\operatorname{IgG}$ comparison $\left(\mathrm{I}^{2:} 0 \%\right.$ and $\left.p=0.837\right)$ (Figure 3 ).

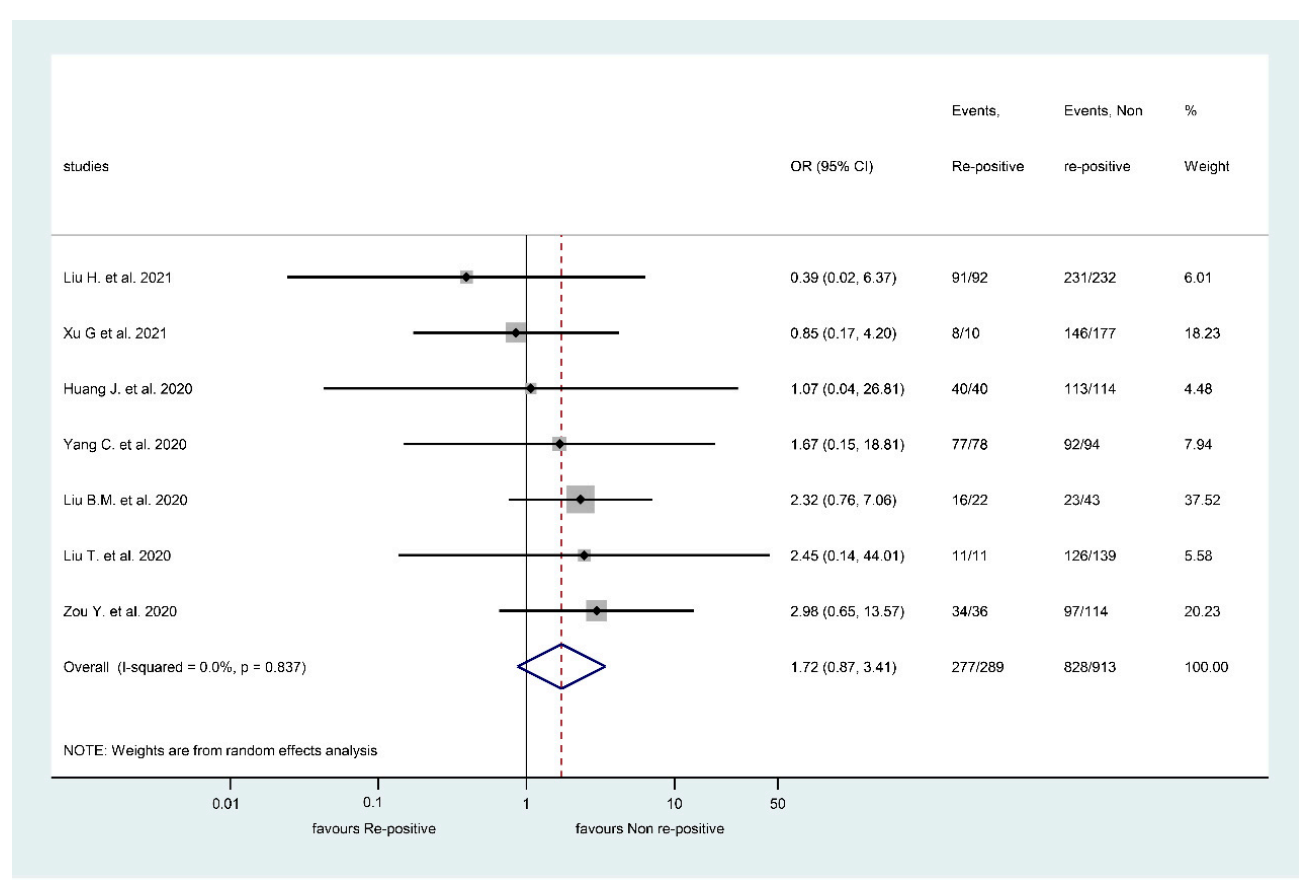

Figure 3. Forest plot representing that repeatedly SARS-CoV-2 positive episode is not associated with Immunoglobulin G positivity. 


\subsubsection{Risk Factors for Repeated SARS-CoV-2 Positivity}

When comparing patients with mild COVID-19 with those with non-mild cases during the first episode, we found decreased odds of presenting repeated PCR positivity in the mild group (Table 2). Except for this comparison, the other risk factors showed no statistically significant difference.

Table 2. Results of the analyses on risk factors.

\begin{tabular}{|c|c|c|c|c|c|}
\hline Risk Factor & Effect Size in OR & $95 \%$ CI & $p$-Value & Heterogeneity $\left(\mathrm{I}^{2}\right)($ in $\%)$ & $p$-Value for the $\chi^{2}$ Test of Heterogeneity \\
\hline Mild first episode & 0.3 & $0.14-0.67$ & 0.003 & 81 & $<0.001$ \\
\hline Severe first episode & 0.66 & $0.41-1.07$ & 0.095 & 62.6 & $<0.001$ \\
\hline Gender & 1.10 & $0.97-1.25$ & 0.146 & 0 & 0.57 \\
\hline Risk Factor & Effect Size in WMD & $95 \%$ CI & $p$-Value & Heterogeneity $\left(\mathrm{I}^{2}\right)$ (in $\left.\%\right)$ & $p$-Value for the $\chi^{2}$ Test of Heterogeneity \\
\hline Age & -1.93 years & $-4.49-0.63$ & 0.139 & 84.1 & $<0.001$ \\
\hline Body mass index & $0.10 \mathrm{~kg} / \mathrm{m}^{2}$ & $-0.72-0.92$ & 0.818 & 60.5 & 0.027 \\
\hline Length of hospital stay & -0.14 days & $-1.50-1.22$ & 0.837 & 81.9 & $<0.001$ \\
\hline
\end{tabular}

Bold text: Statistically significant difference.

Forest plots for risk factors are presented in Supplementary Figures S1-S6.

\subsection{Risk of Bias Assessment}

Supplementary Figures S11-S18 show the results of the risk of bias assessment. The publication bias could only be assessed for age, gender, length of hospitalization, and severity of COVID-19 infection. Only when comparing mean differences in age between groups did there appear a significant publication bias $(p=0.001)$.

\section{Discussion}

One of our most important findings is that repeated or prolonged COVID-19-PCR positivity may lead to a higher chance of the presence of IgG antibodies. It might be that those individuals who have long-term viral shedding will have a more prominent immune response. We found that a milder disease course might be associated with a higher rate of repositivity. The underlying cause of this finding could be that the milder infection does not initiate a strong immune response.

A Chinese study of 284 patients reported $100 \%$ IgG positivity after recovery from the first infection [11]. An Italian study also described that spike (receptor binding domain) RBD-IgG is present in more than $96.5 \%$ of the patients after four weeks of the infection [56]. Although these results look promising, during COVID-19 infection, multiple types of antibodies can develop [11]. A study showed that the antigens' persistence also depends on the analytical kit used for the detection [57]. These can be associated with different immunity and risk for future PCR positivity, which should be the focus of future investigations. Another issue that can be addressed in more detail in the future is the measurement of neutralizing antibodies, although an increasing number of studies are dealing with the topic. A longitudinal study that involved 517 patients concluded that the dynamic of the neutralizing antibody response in patients who have recovered from COVID-19 infection is variable and could only be assessed on an individual level [58]. Prediction of reinfection or repositivity could be facilitated by knowing the titer of neutralizing antibodies.

Our analysis did not find an association between age and repeated positivity. In a meta-analysis of thirteen studies, the authors describe an increased risk for severe disease course if the patient is older than 65 years [59]. This result indirectly suggests that once elderly patients recover, they are not at risk for repeated positivity, although more data are needed to clarify this question. A population-based study observed that patients younger than 65 are least protected against a repeated infection [14]. We did not find a significantly different gender ratio between the RSP and non-RSP patients.

Several previous works identified obesity as a risk factor for severe COVID-19 infection $[60,61]$. Despite these findings, we could not prove that BMI is associated with RSP. 
Neither the length of hospitalization nor the severity of the first episode seem to influence the risk for RSP. On the other hand, the higher mortality rate of severe and critical disease groups might be a confounding factor. Therefore, our results should be assessed critically, as no previous works attempted to evaluate the potential role of length of hospitalization and severity on repeated positivity.

\subsection{Strengths and Limitation}

Our study group implemented a rigorous methodology while completing the most up-to-date comprehensive work on the topic of potential risk factors of repeated COVID19 positivity.

This meta-analysis carries multiple limitations. Repeated PCR positivity might be caused by relapse, reinfection, prolonged viral shedding, or false-positive PCR tests. To help with differentiation, we collected available data about viral loads and cyclic threshold $(\mathrm{Ct})$ values that the studies used for the diagnosis. A total of 13 studies reported the $\mathrm{Ct}$ values for the PCR positivity, which changed between 37 and 40, which is higher than the recommendation of the Centers for Disease Control and Prevention, which propose a Ct value of 33 [62]. Most of the included articles did not differentiate between these conditions. Furthermore, the follow-up time of the included patients was 14-58 days, which makes re-infection unlikely.

High and moderate risk of bias among the included cohort studies primarily resulted from the differences in patients' baseline characteristics and the imprecisely defined confounding factors.

\subsection{Implication for Practice}

We suggest the follow-up of COVID-19 convalescent patients in terms of antibody positivity to identify IgG negative patients, as they might be more prone to repeated positivity. We also encourage checking IgG positivity in the general population to assess possible asymptomatic patients' immune status.

\subsection{Implication for Research}

We emphasize the importance of future follow-up studies on convalescent COVID-19 patients to assess the potential differences and risk factors of repeatedly and non-repeatedly positive patients. We also propose conducting serological studies to have a clearer view of the different immunoglobulins' roles.

\section{Conclusions}

Our analysis concluded that immunoglobulin $\mathrm{G}$ negativity might be associated with repeated COVID-19 PCR positivity. Age, male gender, body mass index, length of hospitalization and severe infection during the first episode do not seem to influence the risk of repeated positivity, although mild initial infection showed higher odds for repeated positivity after hospital discharge or recovery. However, prospective follow-up studies focusing on this topic are required.

Supplementary Materials: https:/ / www.mdpi.com/article/10.3390/v13050809/s1, Figure S1: Forest plot representing that patients' age does not have a significant impact on repeated SARS-CoV-2 positivity, Figure S2: Forest plot representing that patients' gender does not have a significant impact on repeated SARS-CoV-2 positivity, Figure S3: Forest plot representing that body mass index does not have a significant impact on repeated SARS-CoV-2 positivity, Figure S4: Forest plot representing that the severity of the initial infection does have a significant impact on repeated SARS-CoV-2 positivity, Figure S5: Forest plot representing that severity of the initial infection does not have a significant impact on repeated SARS-CoV-2 positivity, Figure S6: Forest plot representing that length of hospital stay during the initial infection does not have a significant impact on repeated SARS-CoV-2 positivity, Figure S7: Funnel plot of the studies reporting on age of the patient, Figure S8: Funnel plot of the studies reporting on sex of the patient, Figure S9: Funnel plot of the studies reporting on the rate of severe cases during the initial infection, Figure S10: Funnel plot of the studies reporting on the length 
of hospital stay during the initial infection, Figure S11: Risk of bias assessment on study level [A] and across studies [B] comparing patients age in the repeatedly SARS-CoV-2 positive and non-positive patients, Figure S12: Risk of bias assessment on study level [A] and across studies [B] comparing patients gender in the repeatedly SARS-CoV-2 positive and non-positive patients, Figure S13: Risk of bias assessment on study level [A] and across studies [B] comparing IgG positivity in the repeatedly SARS-CoV-2 positive and non-positive patients, Figure S14: Risk of bias assessment on study level [A] and across studies [B] comparing IgM positivity in the repeatedly SARS-CoV-2 positive and non-positive patients, Figure S15: Risk of bias assessment on study level [A] and across studies [B] comparing the proportion of severe cases in the first infection in repeatedly SARS-CoV-2 positive and non-positive patients, Figure S16: Risk of bias assessment on study level [A] and across studies [B] comparing the proportion of mild cases in the first infection in repeatedly SARS-CoV-2 positive and non-positive patients, Figure S17: Risk of bias assessment on study level [A] and across studies [B] comparing length of hospital stay during the first infection in repeatedly SARS-CoV-2 positive and non-positive patients, Figure S18: Risk of bias assessment on study level [A] and across studies [B] comparing body mass index (BMI) in repeatedly SARS-CoV-2 positive and non-positive patients.

Author Contributions: P.H. and F.D. conceived the study; S.K. and S.V. wrote the protocol; L.S. and B.T. did the literature search; B.T. and S.B. screened the records and extracted the data; R.N. and D.D. assessed the quality of included studies; N.F. did the statistical analysis; S.V. prepared the tables; S.V. and L.S. wrote the first draft of this manuscript; A.P., B.E., Z.P., and P.H. supervised the manuscript and approved the submitted draft; Z.P. is the guarantor of this paper and, as an infectious disease specialist, provided the team with an expert background; Z.V. participated in the performance of major revision; All authors have read and agreed to the published version of the manuscript.

Funding: Funding was provided by an Economic Development and Innovation Operative Programme Grant (GINOP 2.3.2-15-2016-00048, GINOP-2.3.4-15-2020-00010) and by a Human Resources Development Operational Programme Grant (EFOP-3.6.2-16-2017-00006), both co-financed by the European Union (European Regional Development Fund) within the framework of the Széchenyi 2020 Program. Furthermore, funding was provided by János Bolyai Research Scholarship of Hungarian Academy of Sciences (to AP), and the ÚNKP20-3, a New National Excellence Program of the Ministry for Innovation and Technology from the source of the National Research Development and Innovation Fund (for SV). Sponsors had no role in the design, data collection, analysis, interpretation, and manuscript preparations.

Ethical Approval: No ethical approval was required for this review, as all data were already published in peer-reviewed journals. No patients were involved in the design, conduct, or interpretation of our review. The datasets used in this study can be found in the full-text articles used in the systematic review and meta-analysis.

Institutional Review Board Statement: Not applicable.

Informed Consent Statement: Not applicable.

Data Availability Statement: The datasets used in this study can be found in the full-text articles used in this systematic review.

Conflicts of Interest: The authors declare no conflict of interest. The funders had no role in the design of the study; in the collection, analyses, or interpretation of data; in the writing of the manuscript, or in the decision to publish the results.

\section{References}

1. WHO Coronavirus Disease (COVID-19) Dashboard. 2021. Available online: https://covid19.who.int/ (accessed on 16 March 2021).

2. Dao, T.L.; Hoang, V.T.; Gautret, P. Recurrence of SARS-CoV-2 viral RNA in recovered COVID-19 patients: A narrative review. Eur. J. Clin. Microbiol. Infect. Dis. 2021, 40, 13-25. [CrossRef]

3. Jokinen, S.; Österlund, P.; Julkunen, I.; Davidkin, I. Cellular Immunity to Mumps Virus in Young Adults 21 Years after MeaslesMumps-Rubella Vaccination. J. Infect. Dis. 2007, 196, 861-867. [CrossRef]

4. Lafaie, L.; Célarier, T.; Goethals, L.; Pozzetto, B.; Grange, S.; Ojardias, E.; Annweiler, C.; Botelho-Nevers, E. Recurrence or Relapse of COVID-19 in Older Patients: A Description of Three Cases. J. Am. Geriatr. Soc. 2020, 68, 2179-2183. [CrossRef]

5. Tillett, R.L.; Sevinsky, J.R.; Hartley, P.D.; Kerwin, H.; Crawford, N.; Gorzalski, A.; Laverdure, C.; Verma, S.C.; Rossetto, C.C.; Jackson, D.; et al. Genomic evidence for reinfection with SARS-CoV-2: A case study. Lancet Infect. Dis. 2021, 21, 52-58. [CrossRef] 
6. Van Elslande, J.; Vermeersch, P.; Vandervoort, K.; Wawina-Bokalanga, T.; Vanmechelen, B.; Wollants, E.; Laenen, L.; André, E.; Van Ranst, M.; Lagrou, K.; et al. Symptomatic SARS-CoV-2 reinfection by a phylogenetically distinct strain. Clin. Infect. Dis. 2020. [CrossRef]

7. Váncsa, S.; Dembrovszky, F.; Farkas, N.; Szakó, L.; Teutsch, B.; Bunduc, S.; Nagy, R.; Párniczky, A.; Erőss, B.; Péterfi, Z.; et al. Repeated SARS-CoV-2 Positivity: Analysis of 123 Cases. Viruses 2021, 13, 512. [CrossRef]

8. Murchu, E.O.; Byrne, P.; Walsh, K.A.; Carty, P.G.; Connolly, M.; De Gascun, C.; Jordan, K.; Keoghan, M.; O'Brien, K.K.; $\mathrm{O}^{\prime}$ Neill, M.; et al. Immune response following infection with SARS-CoV-2 and other coronaviruses: A rapid review. Rev. Med. Virol. 2020, e2162. [CrossRef]

9. Bao, L.; Deng, W.; Gao, H.; Xiao, C.; Liu, J.; Xue, J.; Lv, Q.; Liu, J.; Yu, P.; Xu, Y.; et al. Reinfection could not occur in SARS-CoV-2 infected rhesus macaques. bioRxiv 2020. [CrossRef]

10. Arafkas, M.; Khosrawipour, T.; Kocbach, P.; Zielinski, K.; Schubert, J.; Mikolajczyk, A.; Celinska, M.; Khosrawipour, V. Current meta-analysis does not support the possibility of COVID-19 reinfections. J. Med. Virol. 2021, 93, 1599-1604. [CrossRef] [PubMed]

11. Long, Q.X.; Liu, B.Z.; Deng, H.J.; Wu, G.C.; Deng, K.; Chen, Y.K.; Liao, P.; Qiu, J.F.; Lin, Y.; Cai, X.F.; et al. Antibody responses to SARS-CoV-2 in patients with COVID-19. Nat. Med. 2020, 26, 845-848. [CrossRef] [PubMed]

12. He, S.; Zhou, K.; Hu, M.; Liu, C.; Xie, L.; Sun, S.; Sun, W.; Chen, L. Clinical characteristics of "re-positive" discharged COVID-19 pneumonia patients in Wuhan, China. Sci. Rep. 2020, 10, 17365. [CrossRef] [PubMed]

13. Lumley, S.F.; O’Donnell, D.; Stoesser, N.E.; Matthews, P.C.; Howarth, A.; Hatch, S.B.; Marsden, B.D.; Cox, S.; James, T.; Warren, F.; et al. Antibody Status and Incidence of SARS-CoV-2 Infection in Health Care Workers. N. Engl. J. Med. 2020, 384, 533-540. [CrossRef] [PubMed]

14. Hansen, C.H.; Michlmayr, D.; Gubbels, S.M.; Mølbak, K.; Ethelberg, S. Assessment of protection against reinfection with SARS-CoV-2 among 4 million PCR-tested individuals in Denmark in 2020: A population-level observational study. Lancet 2021, 397, 1204-1212. [CrossRef]

15. Moher, D.; Liberati, A.; Tetzlaff, J.; Altman, D.G. Preferred reporting items for systematic reviews and meta-analyses: The PRISMA statement. Ann. Intern. Med. 2009, 151, 264-269. [CrossRef] [PubMed]

16. Higgins, J.P.; Thomas, J.; Chandler, J.; Cumpston, M.; Li, T.; Page, M.J.; Welch, V.A. (Eds.) Cochrane Handbook for Systematic Reviews of Interventions Version 6.1 (Updated September 2020) Cochrane. 2020. Available online: www.training.cochrane.org/ handbook (accessed on 16 March 2021).

17. Riley, R.D.; Moons, K.G.M.; Snell, K.I.E.; Ensor, J.; Hooft, L.; Altman, D.G.; Hayden, J.; Collins, G.S.; Debray, T.P.A. A guide to systematic review and meta-analysis of prognostic factor studies. BMJ 2019, 364, k4597. [CrossRef] [PubMed]

18. Hayden, J.A.; van der Windt, D.A.; Cartwright, J.L.; Côté, P.; Bombardier, C. Assessing bias in studies of prognostic factors. Ann. Intern. Med. 2013, 158, 280-286. [CrossRef]

19. DerSimonian, R.; Laird, N. Meta-analysis in clinical trials. Control. Clin. Trials 1986, 7, 177-188. [CrossRef]

20. Higgins, J.P.; Thompson, S.G.; Deeks, J.J.; Altman, D.G. Measuring inconsistency in meta-analyses. BMJ 2003, 327, 557-560. [CrossRef]

21. Hu, R.; Jiang, Z.; Gao, H.; Huang, D.; Jiang, D.; Chen, F.; Li, J. Recurrent Positive Reverse Transcriptase-Polymerase Chain Reaction Results for Coronavirus Disease 2019 in Patients Discharged From a Hospital in China. JAMA Netw. Open 2020, 3, e2010475. [CrossRef]

22. Yuan, B.; Liu, H.-Q.; Yang, Z.-R.; Chen, Y.-X.; Liu, Z.-Y.; Zhang, K.; Wang, C.; Li, W.-X.; An, Y.-W.; Wang, J.-C.; et al. Recurrence of positive SARS-CoV-2 viral RNA in recovered COVID-19 patients during medical isolation observation. Sci. Rep. 2020, 10, 11887. [CrossRef]

23. An, J.; Liao, X.; Xiao, T.; Qian, S.; Yuan, J.; Ye, H.; Qi, F.; Shen, C.; Wang, L.; Liu, Y.; et al. Clinical characteristics of recovered COVID-19 patients with re-detectable positive RNA test. Ann. Transl. Med. 2020, 8, 1084. [CrossRef] [PubMed]

24. Chen, L.Z.; Lin, Z.H.; Chen, J.; Liu, S.S.; Shi, T.; Xin, Y.N. Can elevated concentrations of ALT and AST predict the risk of 'recurrence' of COVID-19? Epidemiol. Infect. 2020, 148, e218. [CrossRef] [PubMed]

25. Chen, S.-L.; Xu, H.; Feng, H.-Y.; Sun, J.-F.; Li, X.; Zhou, L.; Song, W.-L.; Huang, S.-S.; He, J.-L.; Deng, Y.-Y.; et al. Epidemiological and Clinical Findings of Short-Term Recurrence of Severe Acute Respiratory Syndrome Coronavirus 2 Ribonucleic Acid Polymerase Chain Reaction Positivity in 1282 Discharged Coronavirus Disease 2019 Cases: A Multicenter, Retrospective, Observational Study. Open Forum Infect. Dis. 2020, 7. [CrossRef]

26. Du, H.W.; Chen, J.N.; Pan, X.B.; Chen, X.L.; Fang, S.F.; Li, X.Q.; Xia, P.C.; Gao, L.; Lin, H.L.; Chen, L.M.; et al. Prevalence and outcomes of re-positive nucleic acid tests in discharged COVID-19 patients. Eur. J. Clin. Microbiol. Infect. Dis. 2021, 40, 413-417. [CrossRef] [PubMed]

27. Hu, F.; Chen, F.; Ou, Z.; Fan, Q.; Tan, X.; Wang, Y.; Pan, Y.; Ke, B.; Li, L.; Guan, Y.; et al. A compromised specific humoral immune response against the SARS-CoV-2 receptor-binding domain is related to viral persistence and periodic shedding in the gastrointestinal tract. Cell. Mol. Immunol. 2020, 17, 1119-1125. [CrossRef] [PubMed]

28. Hu, J.; Li, S.; Wu, Y.; Xiong, Z.; Yang, Y.; Gong, L.; Tian, F. Surveillance and re-positive RNA test in patients recovered from COVID-19. J. Med. Virol. 2021, 93, 1221-1224. [CrossRef]

29. Huang, J.; Zheng, L.; Li, Z.; Hao, S.; Ye, F.; Chen, J.; Gans, H.A.; Yao, X.; Liao, J.; Wang, S.; et al. Kinetics of SARS-CoV-2 positivity of infected and recovered patients from a single center. Sci. Rep. 2020, 10, 18629. [CrossRef] 
30. Landi, F.; Carfi, A.; Benvenuto, F.; Brandi, V.; Ciciarello, F.; Lo Monaco, M.R.; Martone, A.M.; Napolitano, C.; Pagano, F.; Paglionico, A.; et al. Predictive Factors for a New Positive Nasopharyngeal Swab Among Patients Recovered From COVID-19. Am. J. Prev. Med. 2021, 60, 13-19. [CrossRef]

31. Liu, B.M.; Yang, Q.Q.; Zhao, L.Y.; Xie, W.; Si, X.Y. Epidemiological characteristics of COVID-19 patients in convalescence period. Epidemiol. Infect. 2020, 148, e108. [CrossRef]

32. Liu, C.; Ye, L.; Xia, R.; Zheng, X.; Yuan, C.; Wang, Z.; Lin, R.; Shi, D.; Gao, Y.; Yao, J.; et al. Chest Computed Tomography and Clinical Follow-Up of Discharged Patients with COVID-19 in Wenzhou City, Zhejiang, China. Ann. Am. Thorac. Soc. 2020, 17, 1231-1237. [CrossRef]

33. Liu, T.; Wu, S.; Zeng, G.; Zhou, F.; Li, Y.; Guo, F.; Wang, X. Recurrent positive SARS-CoV-2: Immune certificate may not be valid. J. Med. Virol. 2020, 92, 2384-2386. [CrossRef]

34. Lu, J.; Peng, J.; Xiong, Q.; Liu, Z.; Lin, H.; Tan, X.; Kang, M.; Yuan, R.; Zeng, L.; Zhou, P.; et al. Clinical, immunological and virological characterization of COVID-19 patients that test re-positive for SARS-CoV-2 by RT-PCR. EBioMedicine 2020, 59, 102960. [CrossRef] [PubMed]

35. Shui, T.-J.; Li, C.; Liu, H.-B.; Chen, X.; Zhang, B.-K. Characteristics of recovered COVID-19 patients with recurrent positive RT-PCR findings in Wuhan, China: A retrospective study. BMC Infect. Dis. 2020, 20, 749. [CrossRef]

36. Xiao, Y.; Shi, X.; She, Q.; Chen, Q.; Pan, H.; Zhang, J.; Liu, X.; Wu, H.; Jin, W.; Ke, G.; et al. Exploration of turn-positive RT-PCR results and factors related to treatment outcome in COVID-19: A retrospective cohort study. Virulence 2020, 11, 1250-1256. [CrossRef] [PubMed]

37. Yan, N.; Wang, W.; Gao, Y.; Zhou, J.; Ye, J.; Xu, Z.; Cao, J.; Zhang, J. Medium Term Follow-Up of 337 Patients With Coronavirus Disease 2019 (COVID-19) in a Fangcang Shelter Hospital in Wuhan, China. Front. Med. 2020, 7, 373. [CrossRef]

38. Yang, C.; Jiang, M.; Wang, X.; Tang, X.; Fang, S.; Li, H.; Zuo, L.; Jiang, Y.; Zhong, Y.; Chen, Q.; et al. Viral RNA level, serum antibody responses, and transmission risk in recovered COVID-19 patients with recurrent positive SARS-CoV-2 RNA test results: A population-based observational cohort study. Emerg. Microbes Infect. 2020, 9, 2368-2378. [CrossRef]

39. Ye, H.; Zhao, C.; Yang, L.; Yu, W.; Leng, Z.; Sun, Y.; Xiao, Z.; Zhang, X.; Zheng, L.; Ye, X.; et al. Twelve out of 117 recovered COVID-19 patients retest positive in a single-center study of China. EClinicalMedicine 2020, 26, 100492. [CrossRef]

40. Zheng, J.; Zhou, R.; Chen, F.; Tang, G.; Wu, K.; Li, F.; Liu, H.; Lu, J.; Zhou, J.; Yang, Z.; et al. Incidence, clinical course and risk factor for recurrent PCR positivity in discharged COVID-19 patients in Guangzhou, China: A prospective cohort study. PLoS Negl. Trop. Dis. 2020, 14, e0008648. [CrossRef]

41. Zhu, H.; Fu, L.; Jin, Y.; Shao, J.; Zhang, S.; Zheng, N.; Fan, L.; Yu, Z.; Ying, J.; Hu, Y.; et al. Clinical features of COVID-19 convalescent patients with re-positive nucleic acid detection. J. Clin. Lab. Anal. 2020, 34, e23392. [CrossRef] [PubMed]

42. Zou, Y.; Wang, B.-R.; Sun, L.; Xu, S.; Kong, Y.-G.; Shen, L.-J.; Liang, G.-T.; Chen, S.-M. The Issue of Recurrently Positive Patients Who Recovered From COVID-19 According to the Current Discharge Criteria: Investigation of Patients from Multiple Medical Institutions in Wuhan, China. J. Infect. Dis. 2020, 222, 1784-1788. [CrossRef]

43. Hao, Y.; Li, T.; Zheng, C.; Jin, S. The Role of Albumin/Globulin Ratio in Discharged COVID-19 Patients with Re-Positive Nucleic Acid Detection. J. Inflamm. Res. 2020, 13, 713-717. [CrossRef] [PubMed]

44. Ao, Z.; Li, Y.; Wei, J.; Jiang, J.; Wang, X.; Zhang, P.; Liu, Y.; Yu, H.; Zhu, L.; Wang, X.; et al. Clinical characteristics and potential factors for recurrence of positive SARS-CoV-2 RNA in convalescent patients: A retrospective cohort study. Clin. Exp. Med. 2021, 1-7. [CrossRef]

45. Hong, L.X.; Liu, L.; Lin, A.; Yan, W.H. Risk factors for SARS-CoV-2 re-positivity in COVID-19 patients after discharge. Int. Immunopharmacol. 2021, 95, 107579. [CrossRef] [PubMed]

46. Liu, H.Q.; Yuan, B.; An, Y.W.; Chen, K.J.; Hu, Q.; Hu, X.P.; Zhao, J.; Dong, Y.; Chen, Y.X.; Li, W.X.; et al. Clinical characteristics and follow-up analysis of 324 discharged COVID-19 patients in Shenzhen during the recovery period. Int. J. Med. Sci. 2021, 18, 347-355. [CrossRef] [PubMed]

47. Liu, J.; Lian, R.; Zhang, G.; Hou, B.; Wang, C.; Dong, J.; Yang, L.; Wang, J.; Dai, S.; Chen, L.; et al. Changes in serum virus-specific IgM/IgG antibody in asymptomatic and discharged patients with reoccurring positive COVID-19 nucleic acid test (RPNAT). Ann. Med. 2021, 53, 34-42. [CrossRef]

48. Liu, Y.; Ding, N.; Zhou, S.; Chen, C.; Huang, S.; Lv, Y.; Jiao, D.; Zheng, Y.; Hu, Z.; Xu, C.; et al. Comparison of clinical characteristics between patients with coronavirus disease 2019 (COVID-19) who retested RT-PCR positive versus negative: A retrospective study of data from Nanjing. J. Thorac. Dis. 2020, 12, 6435-6445. [CrossRef]

49. Shi, L.Y.; Cai, Y.P.; Zhang, Y.X.; Lin, Y.L.; Lin, L.S.; Ding, J.Z.; Guo, J.X.; Zhuang, X.B.; Chen, X.Y.; Zeng, Y.M. [A comparison of clinical characteristics between patients with and without "recurrence" RNA positive with COVID-19]. Zhonghua Jie He He Hu Xi Za Zhi 2020, 43, 1066-1070. [CrossRef]

50. Xu, G.; Liu, F.; Ye, M.; Zhao, J.; Li, Q.; Feng, C.; Hu, Y.; Li, Y.; Shi, H.; Zhang, F.; et al. No Evidence of Re-infection or Personto-Person Transmission in Cured COVID-19 Patients in Guangzhou, a Retrospective Observational Study. Front. Med. 2020, 7, 593133. [CrossRef]

51. Yang, Z.; Chen, X.; Huang, R.; Li, S.; Lin, D.; Yang, Z.; Sun, H.; Liu, G.; Qiu, J.; Tang, Y.; et al. Atypical presentations of coronavirus disease 2019 (COVID-19) from onset to readmission. BMC Infect. Dis. 2021, 21, 127. [CrossRef]

52. Zhang, J.; Xu, J.; Zhou, S.; Wang, C.; Wang, X.; Zhang, W.; Ning, K.; Pan, Y.; Liu, T.; Zhao, J.; et al. The characteristics of 527 discharged COVID-19 patients undergoing long-term follow-up in China. Int. J. Infect. Dis. 2021, 104, 685-692. [CrossRef] 
53. Zhao, H.; Zhang, C.; Chen, X.X.; Zhu, Q.; Huang, W.X.; Zeng, Y.L.; Liu, Y.X.; Li, G.J.; Du, W.J.; Yao, J.; et al. The relationship between SARS-COV-2 RNA positive duration and the risk of recurrent positive. Infect. Dis. Poverty 2021, 10, 45. [CrossRef]

54. Zhou, J.; Zhang, J.; Zhou, J.; Yi, H.; Lin, Z.; Liu, Y.; Zhu, M.; Wang, H.; Zhang, W.; Xu, H.; et al. Clinical characteristics of re-positive COVID-19 patients in Huangshi, China: A retrospective cohort study. PLoS ONE 2020, 15, e0241896. [CrossRef]

55. Wu, X.; Wang, Z.; He, Z.; Li, Y.; Wu, Y.; Wang, H.; Liu, Y.; Hao, F.; Tian, H. A follow-up study shows that recovered patients with re-positive PCR test in Wuhan may not be infectious. BMC Med. 2021, 19, 77. [CrossRef] [PubMed]

56. Secchi, M.; Bazzigaluppi, E.; Brigatti, C.; Marzinotto, I.; Tresoldi, C.; Rovere-Querini, P.; Poli, A.; Castagna, A.; Scarlatti, G.; Zangrillo, A.; et al. COVID-19 survival associates with the immunoglobulin response to the SARS-CoV-2 spike receptor binding domain. J. Clin. Investig. 2020, 130, 6366-6378. [CrossRef] [PubMed]

57. Favresse, J.; Eucher, C.; Elsen, M.; Gillot, C.; Van Eeckhoudt, S.; Dogné, J.-M.; Douxfils, J. Persistence of Anti-SARS-CoV-2 Antibodies Depends on the Analytical Kit: A Report for Up to 10 Months after Infection. Microorganisms 2021, 9, 556. [CrossRef] [PubMed]

58. Chia, W.N.; Zhu, F.; Ong, S.W.X.; Young, B.E.; Fong, S.-W.; Le Bert, N.; Tan, C.W.; Tiu, C.; Zhang, J.; Tan, S.Y.; et al. Dynamics of SARS-CoV-2 neutralising antibody responses and duration of immunity: A longitudinal study. Lancet Microbe 2021. [CrossRef]

59. Zheng, Z.; Peng, F.; Xu, B.; Zhao, J.; Liu, H.; Peng, J.; Li, Q.; Jiang, C.; Zhou, Y.; Liu, S.; et al. Risk factors of critical \& mortal COVID-19 cases: A systematic literature review and meta-analysis. J. Infect. 2020, 81, e16-e25. [CrossRef]

60. Hussain, A.; Mahawar, K.; Xia, Z.; Yang, W.; El-Hasani, S. RETRACTED: Obesity and mortality of COVID-19. Meta-analysis Obes. Res. Clin. Pract. 2020, 14, 295-300. [CrossRef] [PubMed]

61. Földi, M.; Farkas, N.; Kiss, S.; Zádori, N.; Váncsa, S.; Szakó, L.; Dembrovszky, F.; Solymár, M.; Bartalis, E.; Szakács, Z.; et al. Obesity is a risk factor for developing critical condition in COVID-19 patients: A systematic review and meta-analysis. Obes. Rev. 2020, 21, e13095. [CrossRef]

62. Favresse, J.; Gillot, C.; Oliveira, M.; Cadrobbi, J.; Elsen, M.; Eucher, C.; Laffineur, K.; Rosseels, C.; Van Eeckhoudt, S.; Nicolas, J.-B.; et al. Head-to-Head Comparison of Rapid and Automated Antigen Detection Tests for the Diagnosis of SARS-CoV-2 Infection. J. Clin. Med. 2021, 10, 265. [CrossRef] 